\title{
Larval convergence in a colonial tunicate: the organization of the sarcotubular complex in Ecteinascidia turbinata (Perophoridae, Phlebobranchiata, Tunicata, Chordata)
}

Thomas Stach • Andreas Kirbach

Published online: 9 January 2009

(C) Springer-Verlag 2008

Erratum to: Zoomorphology

DOI 10.1007/s00435-008-0069-1

Due to an unfortunate error the legend of the Fig. 7 was incorrect. The correct legend is given here.

The online version of the original article can be found under doi:10.1007/s00435-008-0069-1.

T. Stach $(\bowtie) \cdot$ A. Kirbach

Institut für Biologie, Chemie, Pharmazie,

Zoologie, Evolution und Systematik der Tiere,

Freie Universität Berlin, Königin-Luise-Straße 1-3,

14195 Berlin, Germany

e-mail: tstach@zoosyst-berlin.de 


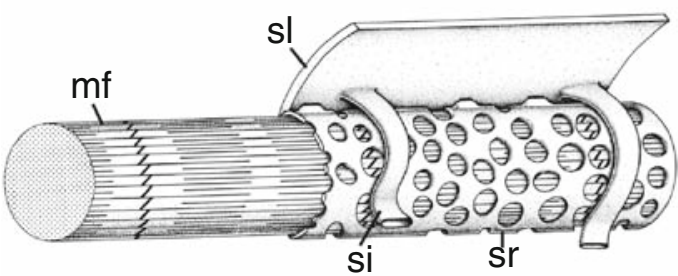

a

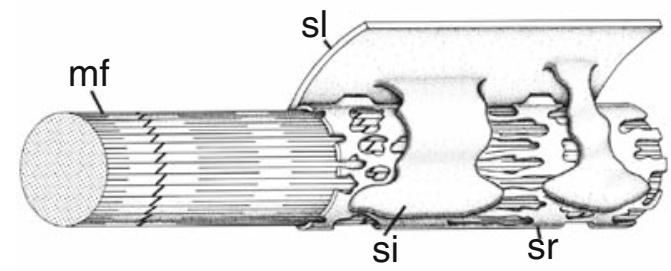

C

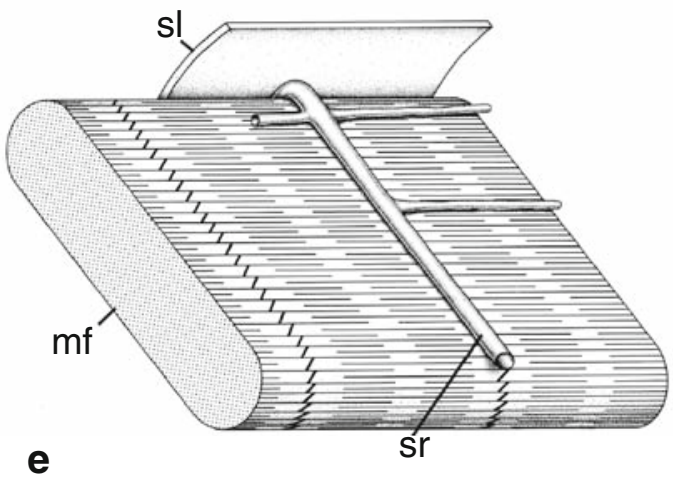

Fig. 7 Schematic representation of different types of the sarcotubular complex found in chordates. See Table 2 for information on taxonomic distribution, meristic variation, and data source. a Flat, tubular invaginations. b Tubular invaginations. $\mathbf{c}$ Laminar invagination. d Invaginations

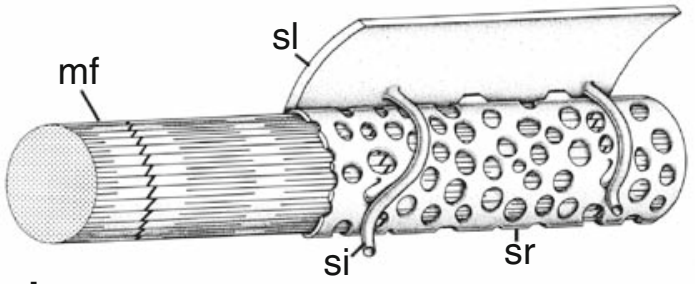

b

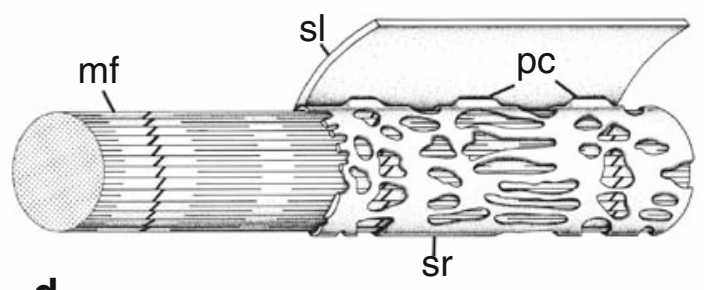

d

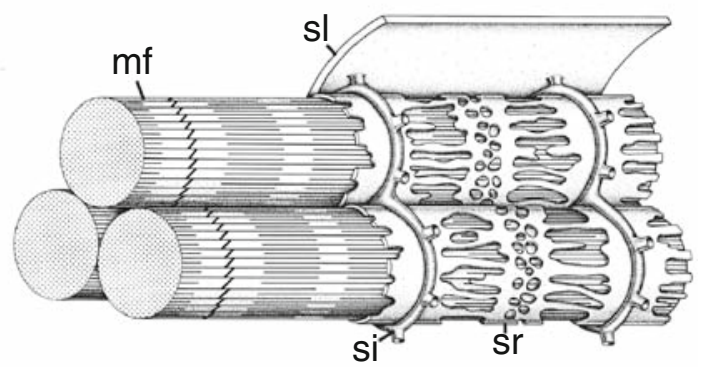

f

lacking. e Invaginations are also lacking in the specialized muscle plates of cephalochordates. f Tubular invaginations in craniates. $m f$ myofibril; $p c$ peripheral coupling; si invagination of the sarcolemma; $s l$ sarcolemma; $s r$ sarcoplasmic reticulum 